\title{
Bioerosion by euendoliths decreases in phosphate-enriched skeletons of living corals
}

\author{
C. Godinot ${ }^{1}$, A. Tribollet ${ }^{2}$, R. Grover ${ }^{1}$, and C. Ferrier-Pagès ${ }^{1}$ \\ ${ }^{1}$ Centre Scientifique de Monaco, CSM, Avenue Saint-Martin, 98000 Monaco, Monaco \\ ${ }^{2}$ Institut de Recherche pour le Développement, UMR IPSL-LOCEAN (IRD/CNRS/UPMC/MNHN), \\ 32 Avenue Henri Varagnat, 93143 Bondy Cedex, France \\ Correspondence to: C. Godinot (cgodinot@ centrescientifique.mc)
}

Received: 17 January 2012 - Published in Biogeosciences Discuss.: 5 March 2012

Revised: 15 May 2012 - Accepted: 5 June 2012 - Published: 2 July 2012

\begin{abstract}
While the role of microboring organisms, or euendoliths, is relatively well known in dead coral skeletons, their function in live corals remains poorly understood. They are suggested to behave like ectosymbionts or parasites, impacting their host's health. However, the species composition of microboring communities, their abundance and dynamics in live corals under various environmental conditions have never been explored. Here, the effect of phosphate enrichment on boring microorganisms in live corals was tested for the first time. Stylophora pistillata nubbins were exposed to 3 different treatments (phosphate concentrations of $0,0.5$ and $2.5 \mu \mathrm{mol}^{-1}$ ) during 15 weeks. After 15 weeks of phosphate enrichment, petrographic thin sections were prepared for observation with light microscopy, and additional samples were examined with scanning electron microscopy (SEM). Euendoliths comprised mainly phototrophic Ostreobium sp. filaments. Rare filaments of heterotrophic fungi were also observed. Filaments were densely distributed in the central part of nubbins, and less abundant towards the apex. Unexpectedly, there was a visible reduction of filament abundance in the most recently calcified apical part of phosphate-enriched nubbins. The overall abundance of euendoliths significantly decreased, from $9.12 \pm 1.09 \%$ of the skeletal surface area in unenriched corals, to $5.81 \pm 0.77 \%$ and $5.27 \pm 0.34 \%$ in 0.5 and $2.5 \mu \mathrm{moll}^{-1}$-phosphate enriched corals respectively. SEM observations confirmed this decrease. Recent studies have shown that phosphate enrichment increases coral skeletal growth and metabolic rates, while it decreases skeletal density and resilience to mechanical stress. We thus hypothesize that increased skeletal growth in the presence of phosphate enrichment occurred too fast
\end{abstract}

for an effective expansion of euendolith growth. They could not keep up with coral growth, so they became diluted in the apex areas as nubbins grew with phosphate enrichment. Results from the present study suggest that coral skeletons of $S$. pistillata will not be further weakened by euendoliths under phosphate enrichment.

\section{Introduction}

Euendoliths are boring phototrophic and organotrophic microorganisms that include cyanobacteria, chlorophytes, rhodophytes, and fungi (Tribollet, 2008a). They develop in a large variety of carbonate substrates, including crustose coralline algal thalli and coral skeletons (Tribollet and Payri, 2001; Tribollet and Golubic, 2005), in which they actively penetrate through active processes of dissolution (Golubic et al., 1981; Garcia-Pichel et al., 2010). They colonize live and dead substrates, although colonization has been shown to be more intense in dead ones (Le Campion-Alsumard et al., 1995a; Tribollet and Payri, 2001). In live coral skeletons, euendoliths grow from the inside of the skeleton towards the surface, trying to keep up with coral growth (Le CampionAlsumard et al., 1995a). In dead skeletons on the contrary, they penetrate from the outside and bore towards the inside of the substratum (Tribollet, 2008b).

In dead corals, euendoliths have been shown to be important primary producers, and major agents of reef bioerosion and sediment production (Schneider and Torunski, 1983; Chazottes et al., 1995; Perry, 2000; Tribollet et al., 2002, 2006; Tribollet and Golubic, 2005). Various environmental 
factors have been reported to affect rates of dissolution by euendoliths in dead substrates. Zubia et al. (2001), Chazottes et al. (2002), and Carreiro-Silva et al. (2005, 2009, 2012) reported enhanced rates of dissolution under eutrophied conditions, while Tribollet and Golubic (2005) and Tribollet (Tribollet, 2008b) showed that terrigenous inputs can mitigate the effects of eutrophication by limiting settlement and penetration of euendoliths. Moreover, it was shown recently that rates of bioerosion by euendolithic communities are positively affected by elevated $p \mathrm{CO}_{2}$ (Tribollet et al., 2009).

In live corals, besides their role as skeleton bioeroders, euendoliths are known to have different activities. Boring heterotrophic fungi appear to inflict damages to their live hosts (Bentis et al., 2000; Alker et al., 2001; Domart-Coulon et al., 2004), while autotrophic euendoliths may provide benefits, especially in cases of bleaching events, through the release of nutrients and organic compounds (Odum and Odum, 1955; Ferrer and Szmant, 1988; Schlichter et al., 1995; Fine and Loya, 2002). The metabolism of euendoliths and the balance between damages and benefits in live corals remain however poorly known (Ferrer and Szmant, 1988; Tribollet, 2008a). In particular, the role of environmental factors on bioerosion of live coral skeletons has been seldom addressed. It was shown that elevated light leads to a photoacclimation of phototrophic euendoliths when increased progressively, and makes them more susceptible to thermal photoinhibition and photodamages when increased rapidly, while concomitant increases in light and temperature lead to a decrease of their photosynthetic efficiency (Fine and Loya, 2002; Fine et al., 2004, 2005). But the roles of other factors such as nutrient concentrations have never been formally examined. Since corals are becoming increasingly impacted by eutrophication due to continuous nutrient release from sewage discharges, rainfall, rivers and ground waters (Tomascik and Sander, 1985; Bell and Tomascik, 1993; McCook, 1999), the impact of nutrients on boring euendolithic communities of live corals deserves more attention.

The aim of the present study was to test the impact of enrichment by a single nutrient, phosphate, under controlled conditions in aquaria, using the tropical coral $S$. pistillata. Phosphate was chosen because it has been reported to affect the skeletal composition and structure of live corals, and to decrease skeletal density (Godinot et al., 2011a; Dunn et al., 2012). Moreover, a recent study on dead shells showed that phosphate stimulates microbioerosion, in particular by boring cyanobacteria (Carreiro-Silva et al., 2012). Since it was shown that live corals are colonized by chlorophytes, cyanobacteria, and fungi (Le Campion-Alsumard et al., 1995a; Priess et al., 2000), we therefore hypothesize that phosphate enrichment can stimulate euendoliths growth in live colonies of $S$. pistillata, and thus rates of carbonate dissolution. S. pistillata was selected for the present study because, in this species, phosphate was already shown to increase tissue and skeletal growth, phosphate incorporation into the mineral fraction of the skeleton, as well as zoox- anthellae specific growth rate, photosynthetic efficiency and phosphorus content (Godinot et al., 2011a). The study of the impact of phosphorus on euendoliths in live S. pistillata will thus improve the understanding of the effects of nutrients on live corals.

\section{Methods}

\subsection{Experimental design}

The experimental setup used in this study has already been described in a previous paper (Godinot et al., 2011a). Briefly, live nubbins (initial size of $1.3 \pm 0.4 \mathrm{~cm}$ long and $0.6 \pm 0.3 \mathrm{~cm}$ in diameter) of $S$. pistillata were cultured in duplicated aquaria under three continuous phosphate enrichments $\left(0,0.5\right.$ and $\left.2.5 \mu \mathrm{moll}^{-1}\right)$. The $0.5 \mu \mathrm{moll}^{-1}$ enrichment represented a phosphate concentration, which has been reported on some eutrophic reefs (Kinsey and Davies, 1979), whereas the $2.5 \mu \mathrm{mol}^{-1}$ enrichment was used to highlight the effect of phosphate on coral physiology. Corals were kept unfed to control for phosphorus enrichment. Light, temperature, salinity, algal development and nutrient concentrations were controlled in each aquarium (Godinot et al., 2011a). Three nubbins per treatment (9 nubbins in total) were sampled for euendolith observations after 15 weeks of phosphate enrichment, and were immediately fixed in a $4 \%$ solution of formaldehyde in buffered seawater.

\subsection{Sample treatment}

Nubbins were cut transversally in two halves for observation of euendoliths with light microscopy and scanning electron microscopy (SEM) respectively.

The first halves were used to prepare longitudinal petrographic thin sections for light microscopy observations. The samples were dehydrated in a series of ethanol and acetone baths, then embedded in Araldite as described by Tribollet (2008b). Several millimeter-thin slabs of skeleton were cut using a diamond circular saw, and were then mounted on microscope slides, ground to the quality of petrographic thin sections, briefly etched with $5 \% \mathrm{HCl}$, rinsed carefully, and stained with $5 \%$ toluidine blue to reveal the euendolithic filaments. Nine to twelve slides were prepared out of the 3 nubbins studied per treatment. We selected 5 good quality slides out of the 9 or 12 slides for measurements of the different biological variables related to boring microflora, after checking that they were representative of all slides per treatment. Sections were observed with a Nikon Eclipse LV100 microscope, on which a Nikon DS-RI1 camera was mounted.

The second halves of samples were used to prepare SEM sections. Samples were bleached with sodium hypochlorite prior to embedding, then cut longitudinally, shortly etched with $5 \% \mathrm{HCl}$, rinsed and dried carefully, and then platinumcoated. Three samples per treatment were observed with a ZEISS Evo.LS.15 environmental SEM. 


\subsection{Analyses}

\subsubsection{Petrographic slides}

Two semi-quantitative methods were selected to determine if phosphate had an effect on the overall distribution of microboring filaments in the skeletons, and to quantify the abundance of filaments in each treatment. In this latter technique, only non-porous areas of the skeleton (i.e. microscopic fields fully covered by skeleton) were selected for repeatability and accuracy of the abundance quantifications. This choice was made because of the highly porous structure of $S$. pistillata skeletons, which was of ca. $50 \pm 8 \%$ (estimated on pictures of the petrographic slides with the software ImageJ).

The first semi-quantitative method consisted in selecting one representative slide out of the five per phosphate treatment to map in detail the spatial distribution of filaments across the entire sections of skeleton, i.e. porous and nonporous areas. For this new approach of euendoliths distribution, pictures of the entire selected thin sections were taken and assembled using the software NIS-Elements D (Nikon). These pictures were converted to binary black and white pictures with ImageJ. The outlines of the skeletons were recovered with the software Adobe Illustrator, and colored distribution maps were drawn within those outlines. Maps were based on estimations of the abundance of euendolithic filaments, visually ranked from 1 to 5 by the same observer (respectively lowest and highest filament abundances encountered across all the samples). Abundances were estimated on $0.14 \mathrm{~mm}^{2}$ optical fields, at ca. $500 \mu \mathrm{m}$ intervals across the whole thin sections (i.e. ca. $150 \pm 25$ measures per sample).

The second semi-quantitative method consisted in ranking the abundance of filaments on 30 randomly selected nonporous microscopic fields of $0.14 \mathrm{~mm}^{2}$ per slide (5 slides, thus 150 measurements per phosphate treatment), in order to quantify and to compare the abundance of filaments among phosphate treatments. We thus observed a total surface area of $0.041 \mathrm{~cm}^{2}$ per slide out of $0.85 \mathrm{~cm}^{2}$ on average, with a porosity of $50 \pm 8 \%$. Thus, quantifications were performed on ca. $10 \%$ of the total surface area of the samples. The same scale as described above (ranks from 1 to 5) was used. To statistically compare the abundance of filaments between phosphate treatments, ranks were matched to percentages of surface area covered by euendoliths. These percentages were determined for each rank of abundance as a preliminary step, using 5 representative photographs per rank, which were analyzed with the software ImageJ. The minimum and maximum values found for each rank gave the range of percentages of bioeroded surface area attributed to that rank (presented in Table 1). The 30 abundance observations performed per slide were thus used to calculate the range of surface area covered by euendoliths on each slide. Medians of these ranges were compared among the three treatments using non-parametric Kruskal-Wallis tests, followed by MannWhitney post-hoc paired $U$-tests, performed with the soft-
Table 1. Range of percentages of bioeroded surface area attributed to each abundance rank for light microscopy measurements. Data are presented as the minimum and maximum value measured out of 5 measurements per rank.

\begin{tabular}{ccr}
\hline \multirow{2}{*}{$\begin{array}{c}\text { Rank of } \\
\text { abundance }\end{array}$} & \multicolumn{2}{c}{$\begin{array}{c}\text { Estimated bioeroded } \\
\text { surface area }\end{array}$} \\
\cline { 2 - 3 } & Min & Max \\
\hline 1 & $0.0 \%$ & $1.0 \%$ \\
2 & $1.0 \%$ & $3.0 \%$ \\
3 & $3.0 \%$ & $7.0 \%$ \\
4 & $7.0 \%$ & $12.0 \%$ \\
5 & $12.0 \%$ & $16.0 \%$ \\
\hline
\end{tabular}

ware StatView. Non-parametric tests were selected since the normality assumption was not respected.

\subsubsection{SEM sections}

SEM sections were observed to confirm the specific diversity of euendoliths observed on petrographic slides, and the semi-quantitative analyses performed. For that latter part, ten pictures were randomly taken per section (30 pictures per phosphate treatment) to quantitatively measure the surface area bioeroded by euendoliths using the software ImageJ (expressed in percent of the total surface area of the picture). The effect of phosphate enrichment was tested using a Kruskal-Wallis test followed by Mann-Whitney post-hoc paired $U$-tests, performed with the software StatView.

\section{Results}

Nubbins measured on average ca. $0.8 \pm 0.3 \mathrm{~cm}$ in diameter at the end of the experiment, with a length of $3.3,3.5$, and $3.7 \pm 1.0 \mathrm{~cm}$ (respectively for the $0,0.5$ and $2.5 \mu \mathrm{mol} 1^{-1}$ treatments).

Euendolithic communities observed in the skeletons of live S. pistillata were mainly composed of Ostreobium sp. filaments (Fig. 1), with possibly fungi filaments as well. No other species were observed.

Those filaments were rather densely distributed in the middle part of the nubbins (yellow to red colors on Fig. 2), while they were less abundant at the apex of the corals (blue to yellow colors on Fig. 2). Differences were observed between the unenriched and the two phosphate-enriched corals (Fig. 2a): in the latter, filaments were even less abundant towards the most recently calcified apical part of the nubbins (large blue and green areas on the right of Fig. 2b and c).

The abundance of euendoliths significantly decreased with phosphate enrichment on the petrographic thin sections, from $9.12 \pm 1.09 \%$ of the non-porous surface area bioeroded in unenriched corals to $5.81 \pm 0.77 \%$ and $5.27 \pm 0.34 \%$ in 0.5 and $2.5 \mu \mathrm{mol}^{-1}$ phosphate-enriched corals respectively 

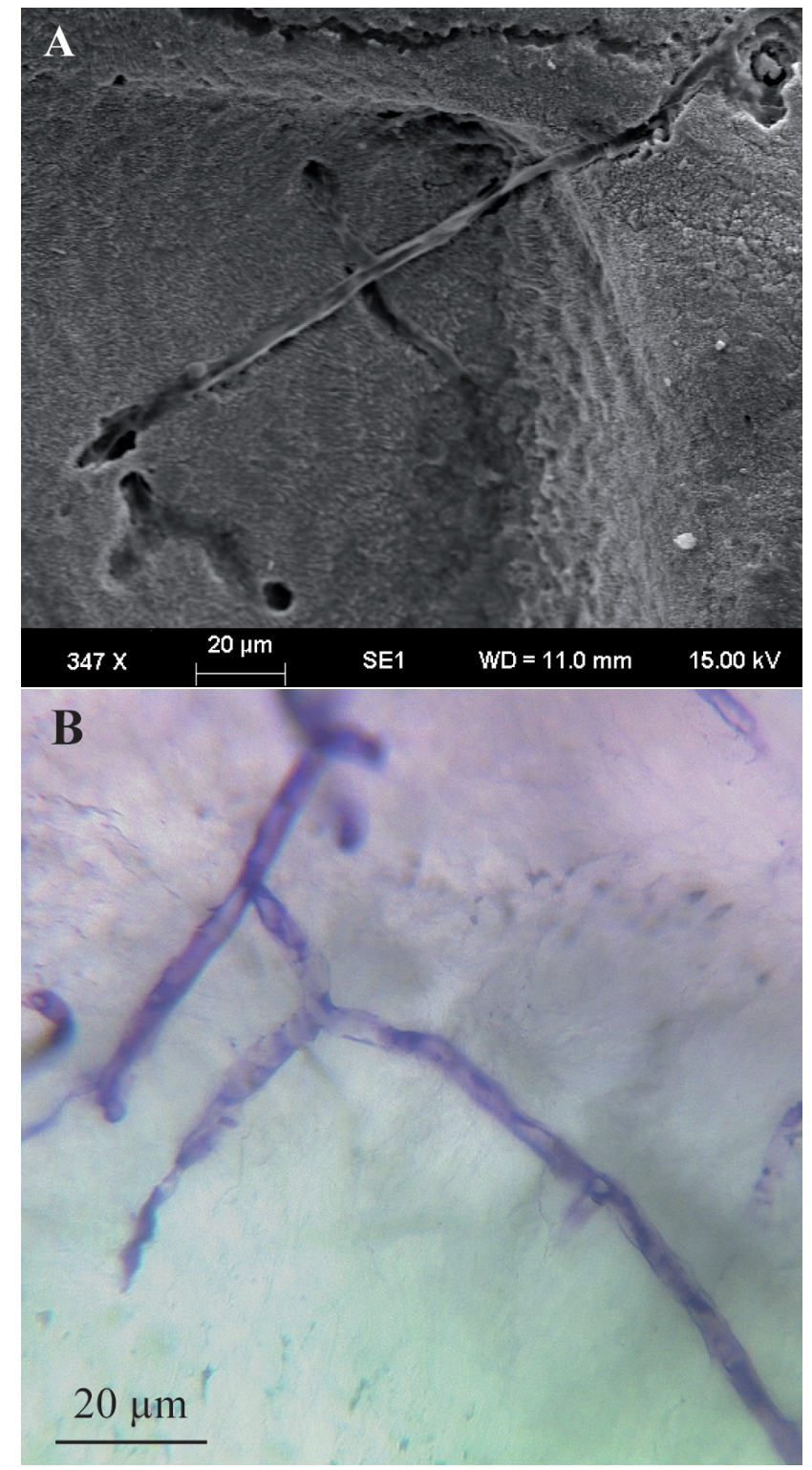

Fig. 1. Filaments of Ostreobium sp. boring inside the skeleton of the coral S. pistillata. (A): photograph of filament sheet and boring traces taken with an environmental scanning electron microscope. (B): photograph of live filaments taken with light microscopy.

(Fig. 3; Kruskal-Wallis test, $\mathrm{df}=2, H=7.58, p=0.02$,). Differences between the two phosphate-enriched treatments were not significant (Mann-Whitney test, $U=10, p=0.60$ ). Bioeroded surface area estimated with SEM confirmed the decrease of abundance with phosphate enrichment (KruskalWallis test, $\mathrm{df}=2, H=6.25, p=0.04)$. Mann-Whitney posthoc tests showed that, with the SEM technique, only the highest phosphate enrichment was significantly different from the other two phosphate treatments $(U=280$, $p=0.018)$.
A

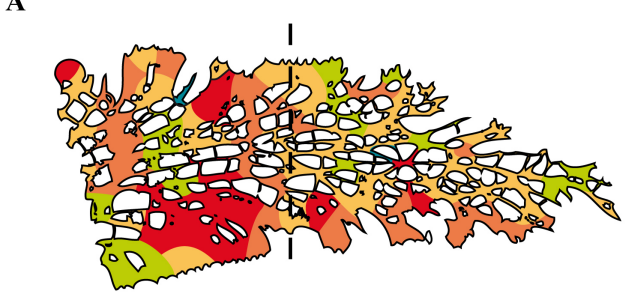

Abundance of euendoliths:

B

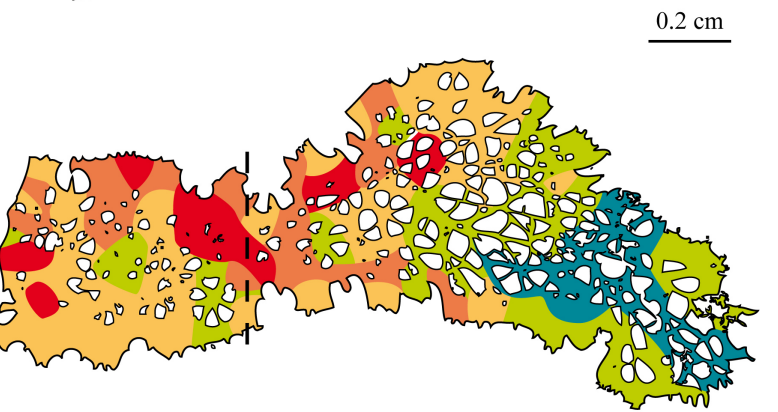

C

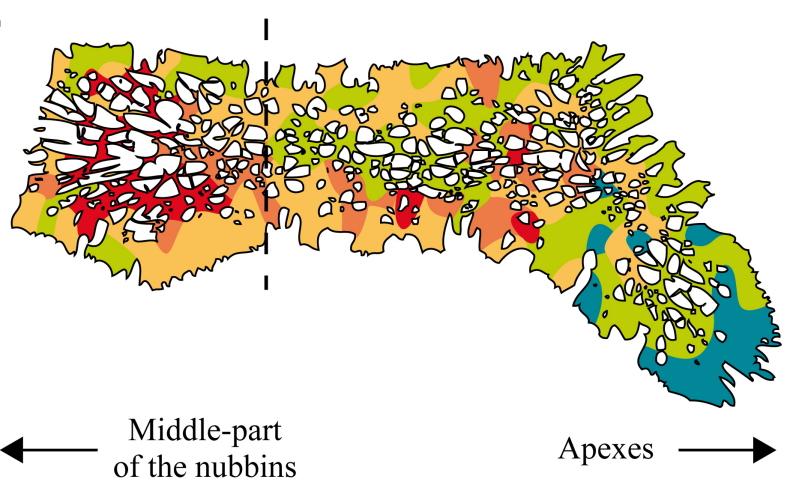

Fig. 2. Effect of long-term phosphate enrichment (15 weeks) on the spatial distribution of euendolithic filaments along the skeleton of $S$. pistillata nubbins: unenriched (A), $0.5 \mu \mathrm{mol} 1^{-1} \mathrm{P}(\mathbf{B})$, and $2.5 \mu \mathrm{mol}^{-1} \mathrm{P}(\mathbf{C})$. Observations were performed with light microscopy on longitudinal petrographic thin section of the nubbins. Maps are based on estimations of the abundance of filaments, visually ranked from 1 (blue, low abundance) to 5 (red, high abundance). Dashed lines mark the nubbin tips at the beginning of the experiment.

\section{Discussion}

This study is, to the best of our knowledge, the first to report on the distribution and abundance of euendoliths colonizing skeletons of live corals in a controlled experiment testing phosphate inputs. Species composition of euendolithic communities observed in S. pistillata is in agreement with the previous few observations made in skeletons of other live corals (Porites; Le Campion-Alsumard et al., 1995a), in which the ubiquitous chlorophyte Ostreobium quekettii dominated assemblages, with occasional filaments of fungi and of the cyanobacterium Plectonema terebrans. In S. pistillata, however, filaments of the cyanobacterium $P$. terebrans were not observed, but may have been overlooked or 


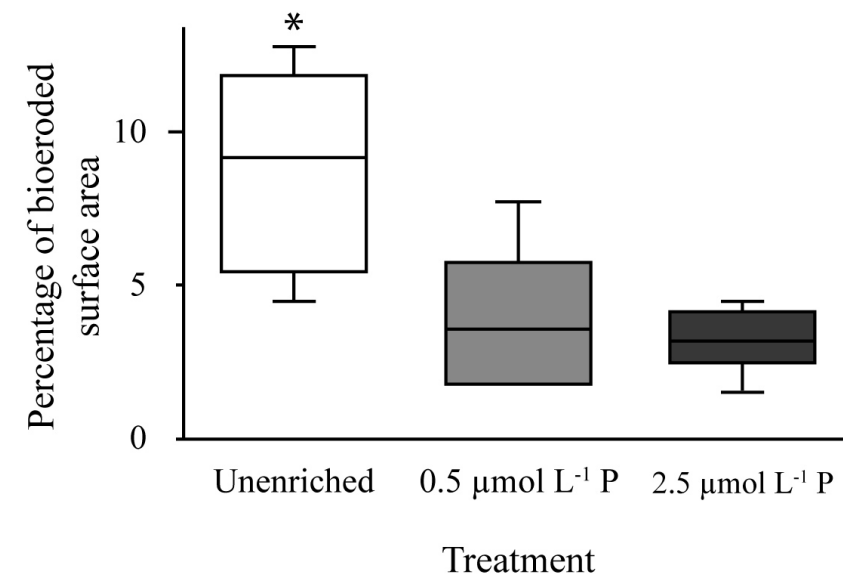

Fig. 3. Abundance of euendoliths estimated through the percentages of surface area bioeroded in each phosphate treatment. Data are presented as Tukey box plots calculated on $n=150$ measurements per treatment. The star indicates treatments significantly different from the others.

confounded with fungi hyphae. The low diversity of euendoliths in S. pistillata confirms that only a few species can penetrate into skeletons of live corals. Euendoliths in S. pistillata were however distributed differently than in Porites colonies. They were localized across the skeletons of $S$. pistillata (unenriched treatment) while they were condensed in a green band beneath the surface of Porites colonies. The above variations in distribution may result from differences in structure, porosity, and growth rates among coral species. This strongly suggests that all coral species are not colonized the same way by euendoliths, as is also the case for dead carbonate substrates (Perry, 1998; Tribollet, 2008a).

If skeletal microdensity decreased in S. pistillata corals due to the continuous 15 weeks phosphate enrichment, similarly to A. muricata corals enriched for 16 weeks with phosphate (Dunn et al., 2012), this decrease did not lead to a faster colonization of the skeleton by euendoliths. On the contrary, euendolith abundance decreased in phosphate-enriched corals, especially in the apexes (Fig. 2). This result may be linked to the increase in skeletal growth rates observed with phosphate enrichment in S. pistillata (Godinot et al., 2011a). An inverse relationship was found between the abundance of euendoliths (expressed as percentages of surface area bioeroded) reported in the present study and the skeletal growth rates reported by Godinot et al. (2011a) (Fig. 4). We thus hypothesize that the increased skeletal growth in the presence of added phosphate was too fast for the euendoliths to actively follow coral growth, and that euendoliths became diluted.

The decrease of euendolithic filament abundance, and thus microbioerosion, reported here was somewhat unexpected. It was in contradiction with the assumption of Dunn et al. (2012), who suggested that colonization by internal bioeroders increases with phosphate eutrophication. However, these authors based their hypotheses on earlier observations

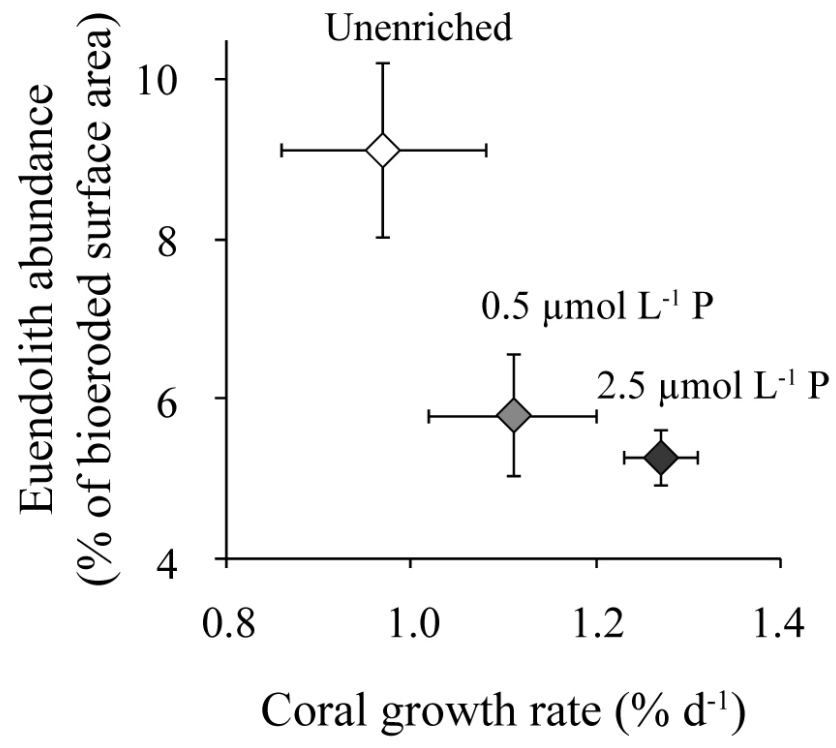

Fig. 4. Relationship between coral skeletal growth rates and the abundance of euendoliths. Skeletal growth rates are from Godinot et al. (2011a) and were measured over 8 weeks of phosphate enrichment. Abundance of euendoliths was estimated based on the percentages of surface area bioeroded in each phosphate treatment after 15 weeks of exposure to phosphate treatments. Data are presented as the means $\pm \mathrm{SE}$, with $n=5$ samples per phosphate treatment for the abundance, and $n=10$ for growth rates.

of dead portions of live colonies of the branching coral Acropora muricata colonized by macroborers made by Sammarco and Risk (1990) and Risk et al. (1995). These latter studies did not report the impact of phosphate on microborers in live parts of the branching coral. The absence of impact of phosphate in the present study is, however, in agreement with the results reported by Carreiro-Silva et al. (2012) in dead substrates, who showed that only cyanobacteria are enhanced by phosphate enrichment. In the present study, the chlorophyte Ostreobium dominated communities.

Eutrophication in general has been reported to increase bioerosion by euendoliths in dead substrates (Zubia and Peyrot-Clausade, 2001; Chazottes et al., 2002; Carreiro-Silva et al., 2005, 2009). Chazottes et al. (2002) and Carreiro-Silva et al. (2005) highlighted the confounding roles of grazing and organic matter release in this positive response, which led to changes in euendolithic communities. These authors hypothesized that increased nutrient concentrations can initiate a feedback loop, where bioerosion by euendoliths and by grazers reinforce one another, leading to accelerated bioerosion of the reef framework. The latter confounding roles of grazing and organic matter release were absent in the present controlled study. Furthermore, the processes of bioerosion in dead substrates and live corals are likely to be very different (Le Campion-Alsumard et al., 1995a). Indeed, in dead substrates, euendoliths are in contact with the ambient seawater, where they can possibly benefit from high 
nutrient concentrations. In live corals, polyps and their symbiotic zooxanthellae form a protective barrier and actively take up the nutrients (D'Elia, 1977; D'Elia et al., 1983; Bythell, 1990; Godinot et al., 2009, 2011a, 2011b). Even though phosphate did reach the skeleton in the present study, as evidenced by the higher $\mathrm{P}: \mathrm{Ca}$ ratio and phosphorus content of the mineral fraction of the skeleton of phosphate-enriched nubbins (Godinot et al., 2011a), it is not granted that this phosphate was available to euendoliths. In fact, phosphate was incorporated as calcium phosphate in the crystal lattice of the skeleton, and was probably not accessible by euendoliths. Another source of phosphate for euendoliths might have been localized within the pores of the skeleton. Indeed, skeletal pore water has been reported to be nutrient-rich in some massive corals (Risk and Müller, 1983; Ferrer and Szmant, 1988), with phosphate concentrations elevated by $0.39 \mu \mathrm{mol}^{-1}$ above those encountered in ambient seawater. However, the main source of inorganic nutrients inside skeletal pore water was suggested to be regeneration by microbial euendoliths themselves rather than the overlying water column (Risk and Müller, 1983; Ferrer and Szmant, 1988). The very poorly connected pore structure of S. pistillata may have prevented circulation of nutrient-enriched skeletal water. Euendoliths in massive corals such as Porites colonies may, however, respond completely differently as those corals have a slow growth rate (Pätzold, 1984) and a structure allowing a better circulation of seawater inside skeleton (Knackstedt et al., 2006).

By addressing issues of bioerosion by euendoliths in the context of nutrient enrichment in live corals, this study adds to the growing body of evidence on the impacts of phosphorus on live corals, and adds to the understanding of euendolith dynamics in this type of substrate. Results from the present study indicate that coral skeletons of S. pistillata will not be further weakened by euendoliths when facing phosphate enrichment. A decrease of microbioerosion rates in phosphate-polluted areas could therefore be positive for living corals facing eutrophication, as it would represent one less stressor to cope with. Indeed, it was shown that when the corals Porites lobata, Pocillopora eydouxi, Acropora cytherea, Acropora humulis, and Montipora studeri are attacked by fungi filaments, they actively resist fungal penetration by depositing conical structures of dense repair aragonite in growing calices (Le Campion-Alsumard et al., 1995b; Bentis et al., 2000). This process is energetically costly, but will likely be reduced if euendoliths become diluted in skeletons of fast growing corals under phosphate enrichment. On the other hand, dilution of phototrophic euendoliths in live coral skeletons may have a negative impact on corals during bleaching events as euendoliths partially replace zooxanthellae, by providing food to their host, and thus a better resistance to thermal stress (Schlichter et al., 1995; Fine and Loya, 2002). Yet, to better understand the role of euendoliths in coral health, and as eutrophic reefs are generally impacted by terrestrial run-off rich in nitrates, ammonium, and organic matter in addition to phosphate, the present study needs to be followed by attempts at determining the separate and combined effects of the different nutrient sources on euendoliths colonizing various coral species and over longer periods of time.

Acknowledgements. We thank Cécile Rottier (CSM) for assistance in coral maintenance and physiological measurements. We thank Thierry Pilorge (LOCEAN) for assistance in sample inclusion. We are grateful to Claire Lazareth (LOCEAN) for help with the cutting and grinding equipment, as well as with the light microscope. We thank Sandrine Caquineau (LOCEAN) for assistance in manipulation of the platinum coater and the SEM. This research was supported by the government of the Principality of Monaco and the Institut de Recherche pour le Développement. Financial support to C. G. was provided by the École Normale Supérieure and the Centre Scientifique de Monaco.

Edited by: H. Kitazato

\section{References}

Alker, A. P., Smith, G. W., and Kim, K.: Characterization of Aspergillus sydowii (Thom et Church), a fungal pathogen of Carribean sea fan corals, Hydrobiologia, 460, 105-111, 2001.

Bell, P. R. F. and Tomascik, T.: The demise of fringing coral reefs of Barbados and of regions in the Great Barrier Reef lagoonimpacts of eutrophication, Proceedings of the Colloquium on Global Aspects of Coral Reefs: Health, Hazards and History, 319-325, 1993.

Bentis, C. J., Kaufman, L., and Golubic, S.: Endolithic fungi in reefbuilding corals (order: Scleractinia) are common, cosmopolitan, and potentially pathogenic, Biol. Bull., 198, 254-260, 2000.

Bythell, J. C.: Nutrient uptake in the reef-building coral Acropora palmata at natural environmental concentrations, Mar. Ecol. Prog. Ser., 68, 65-69, 1990.

Carreiro-Silva, M., McClanahan, T. R., and Kiene, W. E.: The role of inorganic nutrients and herbivory in controlling microbioerosion of carbonate substratum, Coral Reefs, 24, 214-221, doi:10.1007/s00338-004-0445-3, 2005.

Carreiro-Silva, M., McClanahan, T. R., and Kiene, W. E.: Effects of inorganic nutrients and organic matter on microbial euendolithic community composition and microbioerosion rates, Mar. Ecol. Prog. Ser., 392, 1-15, doi:10.3354/meps08251, 2009.

Carreiro-Silva, M., Kiene, W. E., Golubic, S., and McClanahan, T. R.: Phosphorus and nitrogen effects on microbial euendolithic communities and their bioerosion rates, Mar. Pollut. Bull., 64, 602-613, doi:10.1016/j.marpolbul.2011.12.013, 2012.

Chazottes, V., Campion-Alsumard, T. L., and Peyrot-Clausade, M.: Bioerosion rates on coral reefs: interactions between macroborers, microborers and grazers (Moorea, French Polynesia), Palaeogeogr. Palaeocli., 113, 189-198, doi:10.1016/00310182(95)00043-1, 1995.

Chazottes, V., Le Campion-Alsumard, T., Peyrot-Clausade, M., and Cuet, P.: The effects of eutrophication-related alterations to coral reef communities on agents and rates of bioerosion (Reunion Island, Indian Ocean), Coral Reefs, 375-390, doi:10.1007/s00338002-0259-0, 2002. 
D'Elia, C. F.: The uptake and release of dissolved phosphorus by reef corals, Limnol. Oceanogr., 22, 301-315, 1977.

D'Elia, C. F., Domotor, S. L., and Webb, K. L.: Nutrient uptake kinetics of freshly isolated zooxanthellae, Mar. Biol., 75, 157167, 1983.

Domart-Coulon, I. J., Sinclair, C. S., Hill, R. T., Tambutté, S., and Ostrander, G. K.: A basidiomycete isolated from the skeleton of Pocillopora damicornis (Scleractinia) selectively stimulates short-term survival of coral skeletogenic cells, Mar. Biol., 144, 583-592, 2004.

Dunn, J. G., Sammarco, P. W., and LaFleur Jr., G.: Effects of phosphate on growth and skeletal density in the scleractinian coral Acropora muricata: A controlled experimental approach, J. Exp. Mar. Biol. Ecol., 411, 34-44, doi:10.1016/j.jembe.2011.10.013, 2012.

Ferrer, L. M. and Szmant, A. M.: Nutrient regeneration by the endolithic community in coral skeletons, Proceedings of the 6th International Coral Reef Symposium, 1-4, 1988.

Fine, M. and Loya, Y.: Endolithic algae: an alternative source of photoassimilates during coral bleaching, Proc. R. Soc. Lond. B, 269, 1205-1210, 2002.

Fine, M., Steindler, L., and Loya, Y.: Endolithic algae photoacclimate to increased irradiance during coral bleaching, Mar. Freshw. Res., 55, 115-121, 2004.

Fine, M., Meroz-Fine, E., and Hoegh-Guldberg, O.: Tolerance of endolithic algae to elevated temperature and light in the coral Montipora monasteriata from the southern Great Barrier Reef, J. Exp. Biol., 208, 75-81, 2005.

Garcia-Pichel, F., Ramírez-Reinat, E., and Gao, Q.: Microbial excavation of solid carbonates powered by P-type ATPase-mediated transcellular $\mathrm{Ca}^{2+}$ transport, Proc. Natl. Acad. Sci., 107, 2174921754, doi:10.1073/pnas.1011884108, 2010.

Godinot, C., Ferrier-Pagès, C., and Grover, R.: Control of phosphate uptake by zooxanthellae and host cells in the scleractinian coral Stylophora pistillata, Limnol. Oceanogr., 54, 1627-1633, doi:10.4319/lo.2009.54.5.1627, 2009.

Godinot, C., Ferrier-Pagès, C., Montagna, P., and Grover, R.: Tissue and skeletal changes in the scleractinian coral Stylophora pistillata Esper 1797 under phosphate enrichment, J. Exp. Mar. Biol. Ecol., 409, 200-207, doi:10.1016/j.jembe.2011.08.022, 2011a.

Godinot, C., Grover, R., Allemand, D., and Ferrier-Pagès, C.: High phosphate uptake requirements of the scleractinian coral Stylophora pistillata, J. Exp. Biol., 214, 2749-2754, doi:10.1242/jeb.054239, 2011b.

Golubic, S., Friedmann, E. I., and Schneider, J.: The lithobiontic ecological niche, with special reference to microorganisms, J. Sediment. Res., 51, 475-478, doi:10.1306/212f7cb6-2b24-11d78648000102c1865d, 1981.

Kinsey, D. W. and Davies, P. J.: Effects of elevated nitrogen and phosphorus on coral reef growth., Limnol. Oceanogr., 24, 935940, 1979.

Knackstedt, M. A., Arns, C. H., Senden, T. J., and Gross, K.: Structure and properties of clinical coralline implants measured via 3D imaging and analysis, Biomaterials, 27, 2776-2786, doi:10.1016/j.biomaterials.2005.12.016, 2006.

Le Campion-Alsumard, T., Golubic, S., and Hutchings, P.: Microbial endoliths in skeletons of live and dead corals : Porites lobata (Moorea, French Polynesia), Mar. Ecol. Prog. Ser., 117, 149157, 1995a.
Le Campion-Alsumard, T., Golubic, S., and Priess, K.: Fungi in corals symbiosis or disease? Interaction between polyps and fungi causes pearl-like skeleton biomineralization, Mar. Ecol. Prog. Ser., 117, 137-147, 1995b.

McCook, L. J.: Macroalgae, nutrients and phase shifts on coral reefs: scientific issues and management consequences for the Great Barrier Reef, Coral Reefs, 18, 357-367, 1999.

Odum, H. T. and Odum, E. P.: Trophic structure and productivity of a windward coral reef community on Eniwetok atoll, Ecol. Monogr., 25, 291-320, 1955.

Pätzold, J.: Growth rhythms recorded in stable isotopes and density bands in the reef coral Porites lobata (Cebu, Philippines), Coral Reefs, 3, 87-90, doi:10.1007/bf00263758, 1984.

Perry, C. T.: Grain susceptibility to the effects of microboring: implications for the preservation of skeletal carbonates, Sedimentology, 45, 39-51, doi:10.1046/j.1365-3091.1998.00134.x, 1998.

Perry, C. T.: Factors controlling sediment preservation on a North Jamaican fringing reef: a process-based approach to microfacies analysis, J. Sediment. Res., 70, 633-648, doi:10.1306/2dc4092d0e47-11d7-8643000102c1865d, 2000.

Priess, K., Le Campion-Alsumard, T., Golubic, S., Gadel, F., and Thomassin, B. A.: Fungi in corals: black bands and densitybanding of Porites lutea and P. lobata skeleton, Mar. Biol., 136, 19-27, 2000.

Risk, M. J. and Müller, H. R.: Porewater in coral heads: evidence for nutrient regeneration, Limnol. Oceanogr., 28, 1004-1008, 1983.

Risk, M. J., Sammarco, P. W., and Edinger, E. N.: Bioerosion in Acropora across the continental shelf of the Great Barrier Reef, Coral Reefs, 14, 79-86, doi:10.1007/bf00303427, 1995.

Sammarco, P. W. and Risk, M. J.: Large-scale patterns in internal bioerosion of Porites: cross continental shelf trends on the Great Barrier Reef, Mar. Ecol.-Prog. Ser., 59, 145-156, doi:10.3354/meps059145, 1990.

Schlichter, D., Zscharnack, B., and Krisch, H.: Transfer of photoassimilates from endolithic algae to coral tissue, Naturwissenschaften, 82, 561-564, doi:10.1007/bf01140246, 1995.

Schneider, J. and Torunski, H.: Biokarst on limestone coasts, morphogenesis and sediment production, Mar. Ecol., 4, 45-63, doi:10.1111/j.1439-0485.1983.tb00287.x, 1983.

Tomascik, T. and Sander, F.: Effects of eutrophication on reefbuilding corals. I. Growth rate of the reef building coral Monstrea annularis, Mar. Biol., 87, 143-155, 1985.

Tribollet, A.: The boring microflora in modern coral reefs: a review of its roles, in: Current Developments in Bioerosion, edited by: Wisshak, M. and Tapanila, L., Berlin-Heiderlberg, SpringerVerlag, 67-94, 2008a.

Tribollet, A.: Dissolution of Dead Corals by Euendolithic Microorganisms Across the Northern Great Barrier Reef (Australia), Microb. Ecol., 55, 569-580, doi:10.1007/s00248-007-9302-6, 2008 b.

Tribollet, A. and Golubic, S.: Cross-shelf differences in the pattern and pace of bioerosion of experimental carbonate substrates exposed for 3 years on the northern Great Barrier Reef, Australia, Coral Reefs, 24, 422-434, 2005.

Tribollet, A. and Payri, C.: Bioerosion of the coralline alga Hydrolithon onkodes by microborers in the coral reefs of Moorea, French Polynesia, Oceanol. Acta, 24, 329-342, doi:10.1016/s0399-1784(01)01150-1, 2001. 
Tribollet, A., Decherf, G., Hutchings, P., and Peyrot-Clausade, M.: Large-scale spatial variability in bioerosion of experimental coral substrates on the Great Barrier Reef (Australia): importance of microborers, Coral Reefs, 21, 424-432, doi:10.1007/s00338002-0267-0, 2002.

Tribollet, A., Langdon, C., Golubic, S., and Atkinson, M. J.: Endolithic microflora are major primary producers in dead carbonate substrates of Hawaiian coral reefs, J. Phycol., 42, 292-303, 2006.
Tribollet, A., Godinot, C., Atkinson, M. J., and Langdon, C.: Effects of elevated $p \mathrm{CO}_{2}$ on dissolution of coral carbonates by microbial euendoliths, Global Biogeochem. Cy., 23, GB3008.3001-3007, doi:10.1029/2008GB003286, 2009.

Zubia, M. and Peyrot-Clausade, M.: Internal bioerosion of Acropora formosa in Réunion (Indian Ocean): microborer and macroborer activities, Oceanol. Acta, 24, 251-262, doi:10.1016/s03991784(01)01144-6, 2001. 